\title{
Mapping the Learning Needs of Multicultural Generation Z Students
}

\author{
Zariul Antosa $^{1 *}$, Yanuar Kiram ${ }^{2}$, Gusril $^{3}$, and Firman ${ }^{4}$ \\ I*Universitas Negeri Padang, Padang, Indonesia, $ه($ (email), antosazariul@gmail.com.
}

\begin{abstract}
Mapping the learning needs of multicultural generation $\mathrm{Z}$ students is essential. This research is quantitative research which aims to describe the learning needs of multicultural $\mathrm{Z}$ generation students. A learning process has to have a positive atmosphere that encourages students to be Actively Involved in learning. Teachers must develop learning According to Reviews their students' needs. Differences in learning needs and strategies of each generation require teachers to apply different methods so that the learning objectives can be mapped optimally. Currently, university students are called Generation Z or i-generation as they make information technology an integral part of Reviews their lives. Many studies suggest that multicultural generation $\mathrm{Z}$ has a diverse understanding and, Thus, requires a variety of learning methods. Through questionnaires and observations of the learning process, it can be mapped that Reviews their learning needs include open-source and IT-based information, diverse media, flexible multimedia-based learning processes, contextual learning materials, and learning processes were roommate are flexible, responsive, and problem-solving. Besides, they are also growing niche to learn in a group. The results of this study recommend that educators should adapt to the needs and characteristics of students' learning which are dominated by advances in digital technology. They also tend to range to learn in a group. The results of this study recommend that educators should adapt to the needs and characteristics of students' learning, which are dominated by advances in digital technology. They also tend to range to learn in a group. The results of this study recommend that educators should adapt to the needs and characteristics of students' learning which are dominated by advances in digital technology.
\end{abstract}

\section{Keywords: Mapping, Learning Needs, Generation Z}

\section{INTRODUCTION}

A generation describes the circumstances or situations in which every individual has their own life experiences. Currently, the national community has been familiar with the term "Zaman Now, "or it can be called "Millenials". It has become a popular hashtag attached to all aspects of life. The millennial generation is a different modern generation compare to the previous generation on some of the terms referred to as the old generation. Generation $\mathrm{Z}$ hustle bustle of life in the wilds of information and communication technology and modernization. The phenomenon of technology and modernization be a significant element influencing the mindset. Currently, generation $\mathrm{Z}$ are in the age of study at the college level. According to Tapscott (2008), the Z generation is a group that was born in 1998 to 2009, Generation $\mathrm{Z}$ is the latest generation and is the generation that will lead the country and the world in a few decades from now, (Mahazir, Siti Mahani; 2015). According to Karl Mannheim (1893-1947) in his essay entitled "The Problem of Generations" (1923), says that a generation is a group of individuals, who have the same age range, then experienced following the important historical events during a period at the same time (Ken Robert; 2015).
Hootsuite Wearesosial, based on research that is known in January 2019, users social media in Indonesia reached 150 million or approximately $56 \%$ of the total population. The amount is up $20 \%$ from the previous survey. While users of mobile social media (gadgets) to reach 130 million or about $48 \%$ of the population. (www.databoks.katadata.co.id). From the above data, it is known that the majority of Indonesian society technology users through the gadget as social media. According to the social relation, Nurhasanah said generation $\mathrm{Z}$ is done by using smart devices (smartphones) and organize their lives with high confidence. (Nurhasanah, Kompasiana; 2018).

$\mathrm{Z}$ generation dependency on technology is no longer a novelty, openness paths accessible information technology presents a variety of modern facilities, complete, and instant, already embedded in the culture of their lives. The existence of communication media based on IT, such as computers, laptops, gadgets (smartphone), iPad, iPhone, are media interaction that they use for shortcut access to resources such as Youtube, Facebook, Snapchat, Instagram, Vlog, Line, Telegram and Twitter etc. The Instant search process that integrates with their minds principle, "if it can be made easy, why it should be complicated" became the motto of their lives. The 
principle of "if it can be made easy, why it should be complicated" is not a simple thing and messing around, no indication of this principle is also used in the development itself. This principle in lectures serves as a mecca for new learning.

Observing the principle of generation $\mathrm{Z}$ should not be seen as something negative, but the aggressiveness to capture the moment of technological development in the whole venture without being limited resources of time and space. "If it can be made easy, why it should be complicated" should be responded positively, life should not be made more difficult if there were easier way with the principle "implementation" on learning activities. Generation $\mathrm{Z}$ tends to work in groups that allow them to contribute through class discussions to distribute the content they have learned the logic-based learning (Ellizele, 2018). Technological developments can not be denied an integral part of the lives of generations $\mathrm{Z}$. However, there may be important to be revealed, whether with rapid technological developments and the principle of life "If it can be made easy, why should it be complicated" already contribute to the learning activities?

How is the development of technology utilized by the generation $\mathrm{Z}$ has a different cultural background? Is the $\mathrm{Z}$ generation students use technology as part of the learning process or to facilitate the completion of tasks lectures? (Marc Prensky; 2001), an education observer from the United States, once said for our twenty-firstcentury kids, technology is their birthright. Entanglement with the technology of the present generation is inevitable; what matters is how technology in the form of a network, may be directed to something more positive. There is no research has yet been discussing it, how the generation $\mathrm{Z}$ with technological developments in the learning process. Seemiller, C (2016) and St. Martin (2014) says that the learning needs of the generation $\mathrm{Z}$ independent study at their own pace. Nowadays, all universities in Indonesia have made the availability of the wireless network as a mediator between the components of the university, educators and education personnel. Students are facilitated to develop learning through networks provided. Many buildings gazebo made to facilitate the students to access the wireless network. One for us the question as to whether the use of IT development? Is information technology used to process and access teaching materials? How students with different cultural backgrounds (multicultural) utilizing information technology.

As time pass, the generation $\mathrm{Z}$ exploits technology, educators in implementing the learning process has also used the technology. Learning facilities are developed in accordance with technological development. Observing the $\mathrm{Z}$ generation dependency on technology, it should be if teachers and education personnel in developing and making the learning process by treating the $\mathrm{Z}$ generation of students according to their cultural scope. By leveraging their dependence on technology educators, DAPT makes it as a learning resource. It is necessary to recognize the use of technology by the generation $\mathrm{Z}$. The availability of programs and applications that are embedded in a variety of technology products are also used by generations of $\mathrm{Z}$ in the far distance and time to find, develop learning. Access of information in the form of visual and literal user testimonials also science can be used as a reference in the learning process. Based on the above, the research will map out the learning needs of generation $\mathrm{Z}$ with the first indicator) the need for the learning process (Instructional Design). 2) need for fulfillment source.

\section{METHOD}

This research surveys with descriptive method. The study population was students at the University of Riau in the year range 2016 and 2018. According to the year of birth and the age, they belong to generation $\mathrm{Z}$. The authors chose the University of Riau students assuming all generations of $\mathrm{Z}$ according to the development of culture and information technology used in any place in Indonesia is the same. College student characteristics also reflect population distribution of Riau, Indonesia is very heterogenic. Pekanbaru has four dominant tribe ethnic which is Malay, Minang, Batak and Javanese. In this respect, researchers also consider the convenience of conducting correspondence with the respondent. The study population consisted of students year in 2016 (5th semester) and year in 2018 (1st half) are students who use information technology in daily life and using the same learning facilities.

However, the length of time that has been taken in the learning process would bring meaning to them. Differences will certainly also affect the utilization device. Samples were taken by using probability sampling at each study program taking into account the year in, gender and cultural background (tribe). The study population by using a sampling method proposed by Slovin. A total sample of 96 people consisting of 48 men and 48 women. The research data collection tool is a questionnaire and an enclosed observation sheet. Differences will certainly also affect the utilization device. Samples were taken by using probability sampling at each study program taking into account the year in, gender and cultural background (tribe). The study population was taken by using a sampling method proposed by Slovin. The total sample of 96 people consisting of 48 men and 48 women. The research data collection tool is a questionnaire and an enclosed observation sheet. Differences will certainly also affect the utilization device. Samples were taken by using probability sampling at each study program taking into account the year in, gender and cultural background (tribe). The study population was taken by using a sampling method proposed by Slovin. The total sample of 96 people consisting of 48 men and 48 women. The research data collection tool is a questionnaire and an enclosed observation sheet.

The data will be obtained from respondents using a questionnaire (questionnaire) and interview for the survey one data collection method was through a questionnaire (Jackson 2011; 17). According to Denscombe terms of practicality, data collection using the questionnaire is the most popular, including observations, 

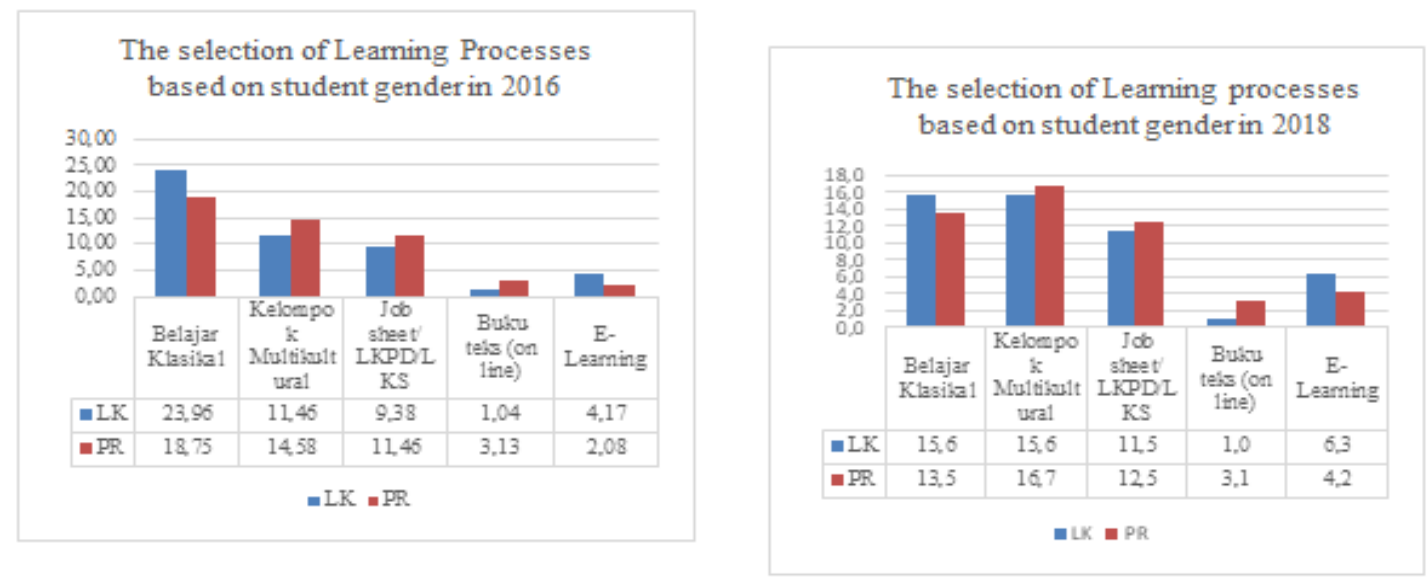

Figure 1 and Figure 2 The Learning Process Students Wanted Sign Year 2016 and 2018 by Gender

interviews, and analysis of documentation. (Denscombe (2010: 57). Questionnaire answer using a scale Gutman (Ankur Joshi 2015-397-398), with assessment standards; 1)Agree / always / very positive given a score of 1,2 ) do not agree / often / positive were given a score of 1 . Data were analyzed through the stages of organizing the data, translate it into the units, synthesize, organize into a pattern, choose what is important and will be used as information research and concluded. (Sugiyono, 2014; 90)

Further data were presented and described with a picture of a systematic, factual and accurate information on the facts found, as well as the relationship between phenomenon investigated (Nazir 1988; 63). Instruments validated by expert judgment based on indicators of research. Through the validation process is assumed to be the instrument used very decent used as an instrument to collect data.

\section{RESULT AND DISCUSSION}

\section{A. Results}

Based on the results of the research data analysis found information about the use of technology by the generation $\mathrm{Z}$ in the learning process. Generation $\mathrm{Z}$ is a next-generation technology that is closely tied to the existence of technology. Based on the results of data processing that has been done, although generation $\mathrm{Z}$ tends to learn independently, the learning process with a multicultural group of their choice. They mostly prefer the learning process that encourages the involvement of technology in the process and find learning resources.

High self-confidence and commitment to achieve the goals through the lecture, be a powerful motivation in the learning process $\mathrm{Z}$. generation based on responses conveyed through a questionnaire that has been distributed, indicated that the generation $\mathrm{Z}$ always feel challenged and feel more meaningful if it contributes in any activity. Educators need to use information technology as an integral part of the learning process to explore all the uniqueness and significance of the information technologies. Based on the following research indicators will be presented research findings of the learning process into their dream as well as teaching materials such as what they need. Based on the analysis of questionnaires that have been spread out to 96 respondents obtained the following results.

\section{Needs Learning Process (instructional design)}

In connection with the indicators of the need for learning or instructional design consists of six subindicators, namely, learning classical, active learning through learning multicultural group with the ProjectBased Learning, inquiry, and Experiment, using job sheet, LKPD or LKS-based multicultural, an online textbook, Homework online, as well as e-learning. Information presented respondents about the needs of the learning process by considering the learning process provides convenience and comfort of psychic accordance with their cultural background. The following data are presented research findings of the learning process desired by the entrance. Based on respondents' answers submitted through the questionnaire obtained the Figure 1 and Figure 2 .

Figure 2 shows student class of 2016 (5th-semester students) by sex (gender), the number of students who want to study in the classical style more than the men. The process of learning is done through a multicultural group work through learning activities, using a learning model Problem-Based Learning, inquiry and experiment with group members from different cultural backgrounds who are favored by men. Similarly, self-learning worksheets or LKPD were developed based on multiculturalism. Ironically, although generation $\mathrm{Z}$ is next-generation technology-based learning, but once on line such as the use of a book, as well as e-learning, is not to their liking. In 2018 most of the younger students love learning through group discussions formed with a different cultural background through learning activities, the model of Problem Based Learning, inquiry or experiment and learning the classical way more favored by women, learning to use a worksheet or LKPD based multicultural preferred by men. Student class of 2018 better reflect the generation $\mathrm{Z}$ for learning by using technology-based 

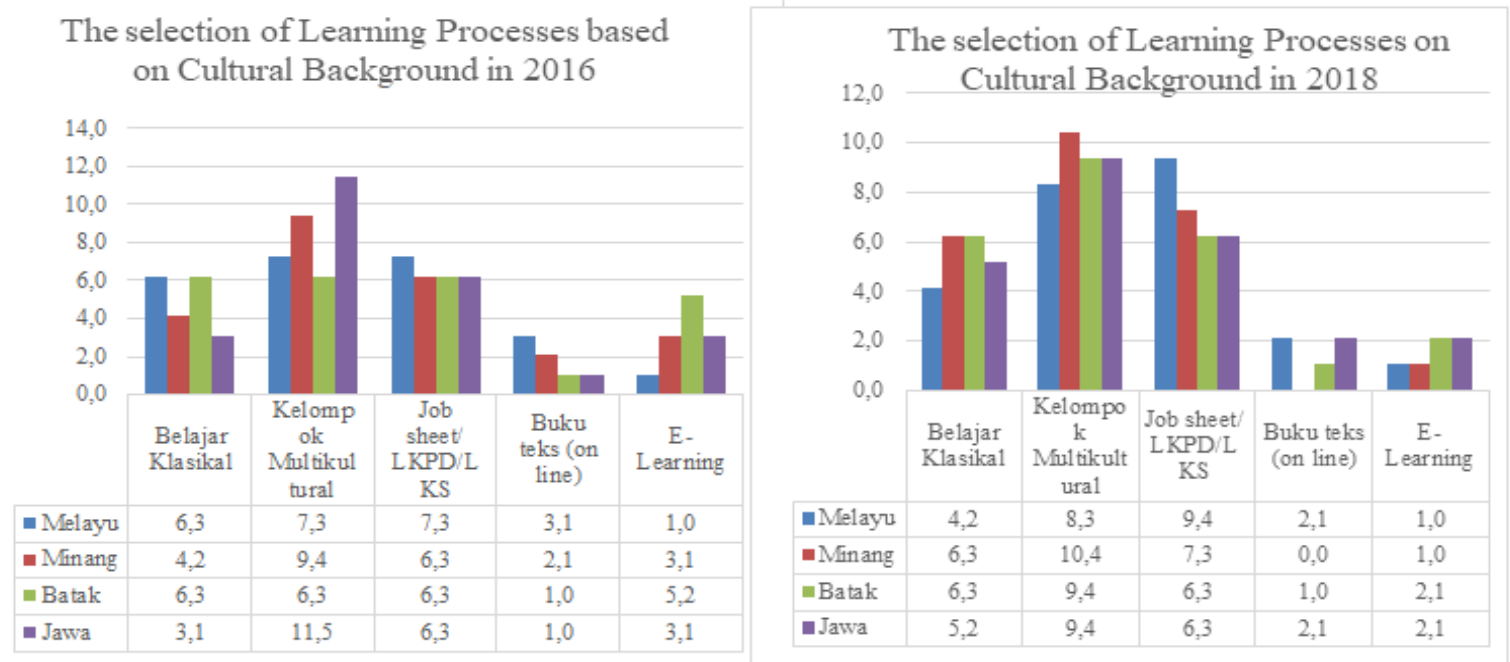

Figure 3 and Figure 4. Learning Process The Wanted Student Year Joined 2016 and 2018 Based on the cultural background of society Malay, Minang, Batak and Java

learning resources such as e-books and e-learning is more liked than the younger students in 2016.

The Figure 3 and Figure 4 are based on the cultural background of the society in Riau province. There are four dominant ethnic groups as the population is ethnic Malay Riau province, ethnic Minang, Batak and Javanese. Based on research data in the Figure 3 and Figure 4 above are known in the student class of 2016. Based on cultural backgrounds, students who come from the Javanese are very fond of learning with a multicultural group discussion, followed by students Minang tribe. The Malays prefer learning by using worksheets and LKPD based multicultural. Classical learning the most favored by the Malays and Batak, however, at least the Tribe wither like e-learning-based learning.

Student class of 2018 from the tribe minang much like learning a multicultural group, as well as the Batak tribe and Java, learning to use a worksheet or multicultural-based LKPD more favored by Malay tribes.
Classical learning more preferably jointly by the Minang and Batak tribe. The process of learning to use ebook and e-learning favored by Batak, Javanese and Malay. Minang Tribe least fond of e-book-based learning. Based on student class of 2016 cultural background better reflect the characteristics of the generation $\mathrm{Z}$ for learning by using technology-based learning resources such as e-books and e-learning is more likable than the student class of 2018.

2.Toward Fulfillment Learning Resources

Learning resources to be the focus of this research is the learning resources that relate to the tendency of generation $\mathrm{Z}$ are always using information technology to the sub-indicators of material in-store WEB e-learning, content distribution via disc or flash drive, a book, youtube and other open access. Following the data obtained from the following research instruments can be seen in Figure 5 and Figure 6.

Based on data collected from student class of
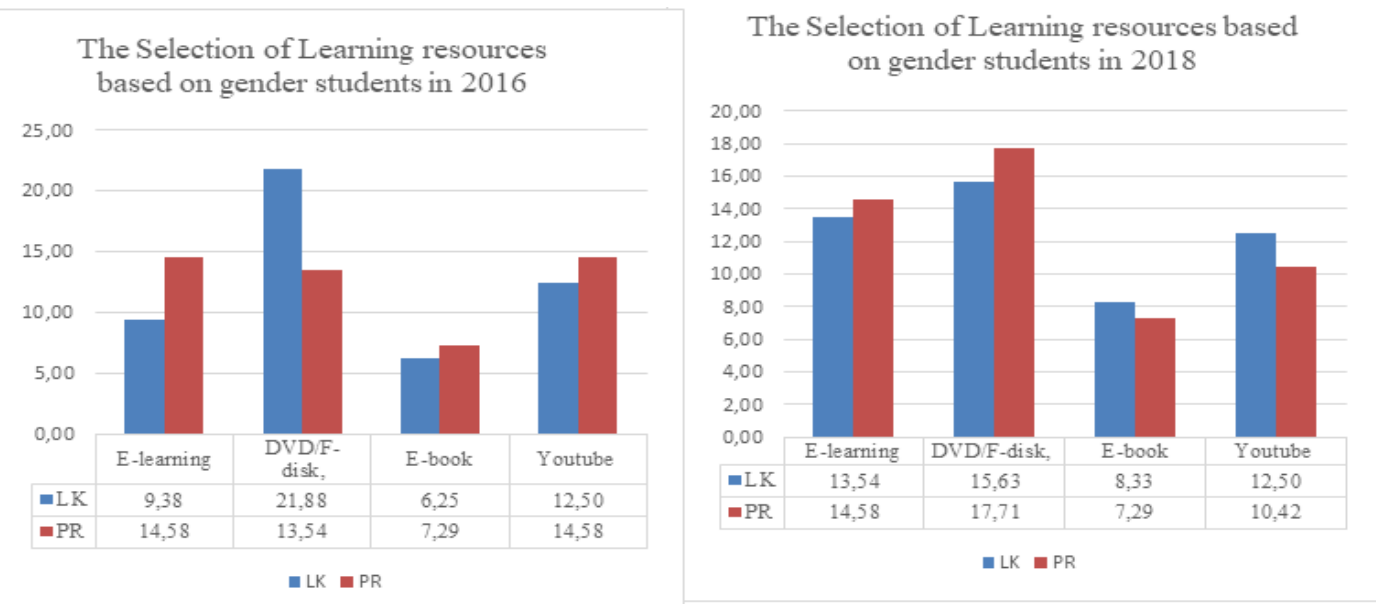

Figure 5 and Figure 6. Sources of Student Learning Needs Year Joined 2016 and 2018 by Gender 

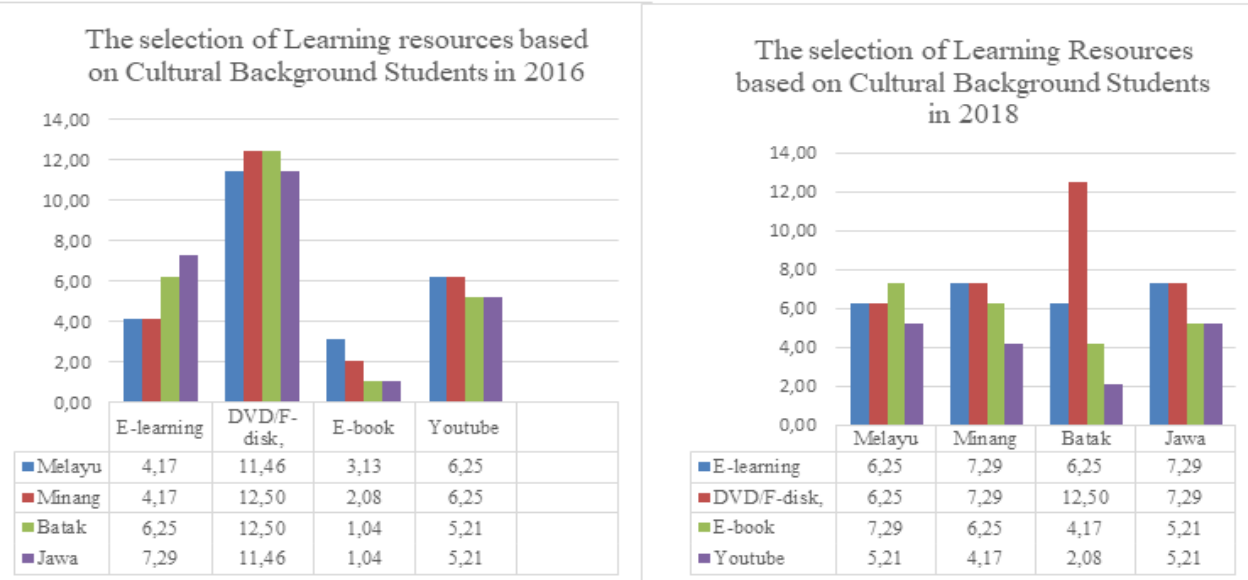

Figure 7 and Figure 8. Sources of Student Learning Needs Year Joined 2016 and 2018 Based on the cultural background

2016, it can be seen in the Figure 5 and Figure 6 shows male students is like the 2016 class of learning materials distributed through the flash more, female students love learning resources on the web e-learning. Based on the Malay ethnic-cultural background, and Javanese, minang like learning through e-learning web, DVD and YouTube, using YouTube as men also favor learning resources. The E-book is a preferred source of learning. In 2018, the student of teaching materials distributed via flash and DVD favored by many students, the next is the material that has been provided on the e-learning website. Male students favor learning resources on YouTube.

Based on the cultural background (Figure 7 and Figure 8), student enrollment year 2016, students from the ethnic Malay, Minang, Batak, and Javanese who want a lot more teaching materials can be distributed through a disc or flash drive. Learning through e-learning preferable by students from Javanese and attended by students from Batak, using YouTube as a source of learning more favored by students who derived from tribal and ethnic Malay Minang. Students from Batak and Javanese are the least student liked learning by using an e-book. The student class of 2018 came from the Batak tribe is much like learning resources are provided in the form of a DVD or flash drive. Students are derived from the Javanese and ethnic Minang preferred source of learning of the elearning and Discs. Students from ethnic Malay preferred source of e-book learning. Youtube is a learning resource that is least favored by students from Batak.

\section{B. Discussion}

The use of the gadget as a high-tech device is a versatile tool that is part of life that they are more concerned with $\mathrm{Z}$ generation is gadget batteries than having breakfast. We suspect that the $\mathrm{Z}$ generation dependency on technology impact on the learning process that they do in daily life. Every day students utilize technology for ordering food, browse cheap laundry places. Communicating with others, shop for fashion, learning tools, beauty tools and sport can be explored by using their gadget. However, the results of this study the use of technology for learning activities, is not so dominant. Students who have passed more than four semesters over not choosing process or technology-based learning resources such as e-learning and YouTube. When viewed with the gadget, they use an average based on Android that allows students to roam the need lectures on the internet more easily; however, it did not happen.

Java community with a resilient culture (Suhardi: 2002: 2) was more like learning resources that take time browsing through the internet is the learning material contained on the website ebook or on YouTube. Instead of the Batak tribe who like hard work and challenges, prefer learning resources contained in the elearning website.

Related to student needs with the desired learning interactions following Figure 1 above overall data obtained from the study sample variations scores on each sub-indicator with a percentage range of $4.17 \%-42.71 \%$, with an interval of $38.54 \%$ on every indicator. Interviews showed that led to the learning process through a diverse group driven by the desire to get diverse information following the custom of each tribe. They use information technology as the average browser information using Gadget. Through the network, they are trying to get information about the habits of other tribes other than members of their group. If the differences observed in addition to the desire for learning information through textbooks and workhouse just demand by $25 \%$. Active learning through the PBL learning model, inquiry and experiment are only interested in $26.04 \%$. Learning through lectures and brainstorming in classical as well as the use of job sheet / LKS / LKPD interest to $63.54 \%$ of the students. Although in the learning process of students from tribes, spirit resilient and high employment are not motivated to engage actively activity of learning to use your technology. Students answered questions questionnaire only limited information they know and maybe done with existing devices. Lecture through brainstorming does not make them involved actively for debriefing process flow, sustainable and can develop in any direction to achieve the learning objectives. The 
brainstorming process does not allow students to access the resources through IT tools at their disposal. While the study by using a job sheet, LKS / LKPD, is not desirable. The job sheet only is done by a few people while others are just waiting for a friend group finished working on the job sheet under the steps of proof theory and the learning process is set by the teacher. Although generation $\mathrm{Z}$ likes things that are logical if confronted with regulated activities, make them interested in this matter following the opinion of Ellizele; (2018).

While the lectures are conducted through the test to review the material in various ways such as written tests, action or quizzes only preferred by $52 \%$ of the students. The most popular are instructional activities through small-group learning with e-learning resources and other resources by $81 \%$. Learning with e-learning and other sources responded very well to students. Each individual as a race to get information with each gadget. Seemiller, C (2016) and. St. Martin (2014) said that the learning needs of generation $\mathrm{Z}$ include study independently and at their own pace seen clearly how the student is trying so hard to find much information as possible through Google searching or looking for their ebook. The process of discussion going well and each student took his idea and the group should accept no railroad.

\section{CONCLUSION}

The essential of mapping the learning results the importance to see learning needs of students. Based on the results, it can be concluded that teachers should apply the variations of method in class. It also can be concluded that open-source and IT-based information, diverse media, flexible multimedia-based learning processes, contextual learning materials, and learning processes were roommate are flexible, responsive, and problem-solving. This results recommend practitioners and educators to adapt the needs and characteristics of students' learning which are dominated by advances in digital technology.

\section{REFERENCES}

[1] Akhmad Sudrajat. (2012). Generation Z and Impilikasinya to Education. https://akhmadsudrajat.wordpress.com/2012/10/0 5/generasi-z-dan implications-to-education /. Retrieved on days Wednesday, January 1st, 2019, 08:00 pm

[2] Joshi1 Ankur (2015) Kale2 Saket, Satish Pal DK Chandel3, and Likert Scale: Explored and Explained. British Journal of Applied Science \& Technology 7 (4): 396-403, 2015, Article no.BJAST.2015.157 ISSN: 2231-0843. international SCIENCEDOMAINwww.sciencedomain.org, DOI: 10.9734 / BJAST / 2015/14975

[3] Brent, JS (2004). Subjective Well-Being And Culture Across Time And Space. Journal of cross- cultural psychology, $34 \quad$ (2), 633 647https://doi.org/10.1177/0022022104270107

[4] Bullen, M.; Morgan, T.; Qayyum, A. (2011) Digital Learners in Higher Education: Generation is Not the Issue. Can. J. Learn. Technol. 1-24. [CrossRef]

[5] Denscombe, M. (2010) "The Good Research Guide for Small-Scale Social Research Projects" fourth edition, Butterworth-Heinemann

[6] Dwidienawati diene; 2018.Understanding Indonesia's Generation Z International Journal of Engineering \& Technology VOL 7. 48. Special edition 245-252 DOI:10.14419 / ijet.v7i3.25.17556

[7] Elizelle Juaneé Cilliers (2018). The Challenge Of Teaching Generation Z, People: International Journal of Social Sciences Vol 3 Special Issue No. 1: 2017 Global Research and Development Series. https: // doi10.20319 / pijss.2017.31.188198

[8] Elizelle Juaneé Cilliers (2018). The Challenge Of Teaching Generation Z, People: International Journal of Social Sciences Vol 3 Special Issue No. 1: 2017 Global Research and Development Series. https: // doi10.20319 / pijss.2017.31.188198

[9] Kathleen AJ, Moh. (2017) Understanding Generation $Z$ Students to Promote a Contemporary Learning Environment. Empowering on Teaching Excellence Journal: Vol. 1: Iss. 1, Article 9.https: //doi10.15142/T3M05T

[10]Ken Roberts (2015) Youth Mobilisations And Political Generations: Young Activists In Political Change Movements During And Since the Twentieth Century. Journal of Youth Studies, Volume 18, 2015-issue 8.https://doi.org/10.1080/13676261.2015.1020937 1

[11]Lancaster and Stillman (2003). When Generations Collide: Who They Are. Why They Clash. How to Solve The Generational Puzzle at Work. Harper Collins.Harper Business; Reprint edition

[12] Lorenzo, G.; Dziuban, C. (2006) Ensuring the Net Generation is Net Savvy. Learn Educause. Initiative, 2, 1-19.

[13] Merriman, M. (2015) What If The Next Big Disruptor is not a What but a Who? Gen $Z$ is Connected, Informed, and Ready for Business. 2015. Available online: https://www.ey.com/Publication/vwLUAssets/EYrise-ofgen-znew-challenge-forretailers/\%24FILE/EY-rise-of-gen-znewchallenge-for- retailers.pdf (accessed on January 23, 2019).

[14] Muhazir, Siti Mahani \& Ismail, Nazlinda (2015). Generation Z: New Labor and Cabarannya. Psychology Articles Year 2015 Title Perkhidmatan Awam 
[15] Nurhasanah (2018) Tempest Generation Z, Andal Tech but Stuttering Undergo process. Kompasiana 12 April 2018

[16] Ponto Julie Ann, Ellington Lee, Suzanne Mellon, Susan L. Beck (2015) Understanding and Evaluating Survey Research, JADPRO (Journal of The Advanced Practioner Oncocology) Mar-Apr 2015. 6 (2): 168-171. PMID: 26649250

[17] Prensky, M. (2001) Digital Natives, Digital Immigrants Part 1. On Horiz., 1-6. [CrossRef]

[18] Swanzen Rica (2018) Facing The Generation Chasm: The Parenting And Teaching Of Generations Y And Z International Journal of Child, Youth, and Family Studies 9 (2): 125-150. http://doi.org/10.18357/ijcyfs92201818216

[19] Schwieger, D.; Ladwig, C. (2018) Reaching and Retaining the Next Generation: Adapting to the Expectations of Gen $\mathrm{Z}$ in the Classroom. Information Systems Education Journal (ISEDJ) 16 (3) ISSN: 1545-679X 45-54 June 2018.

[20] Seemiller, C.; Grace, M. (2016) Generation Z Goes to College; Jossey-Bass: New York, NY, USA,

[21] Soehardi (2002) values of Javanese Culture Oral Tradition ", the online journal Humanities, 3 is derived from (https://journal.ugm.ac.id/jurnalhumaniora/article/view/763/6088, accessed on 20 September 2019)

[22] St. Martin, G. (2014) Generation Z and the Future of Higher Education. Available online: https://news.northeastern.edu/2014/11/19/generati on-z-and-the-future-of-higher-education/ (accessed on January 23, 2019).

[23] Sugiyono (2014) Qualitative and Quantitative Research Methods R \& D, Alfabeta. Duo

[24] Tapscott, Don (2008). Grown Up Digital: How the Net Generation is Changing Your World. Mc.Graw-Hill. 